\title{
Clinical research 101: Why should you care?
}

\author{
Latha G. Stead - Wyatt W. Decker
}

Received: 2 May 2008 / Accepted: 2 May 2008/Published online: 7 June 2008

(C) Springer-Verlag London Ltd 2008

In this issue's Clinical Research Capsule, we ask the fundamental question: "Why care about research?" Clinicians sometimes have a distanced attitude towards research. The reasons for this are many: conducting research is difficult; it is only for those who are statistically minded; it means having NIH or equivalent funding; finally, it does not pertain to them as research is separate from patient care. The notion that research is separate and without impact on patient care could not be more erroneous.

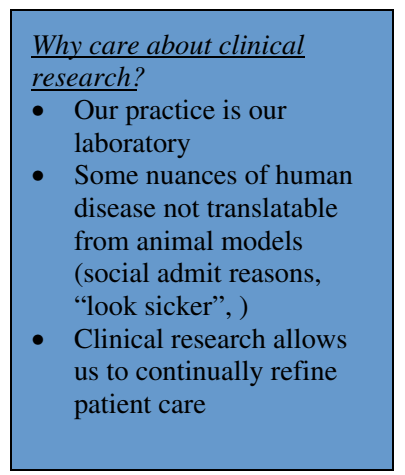

\section{G. Stead - W. W. Decker}

Department of Emergency Medicine,

Mayo Clinic College of Medicine,

Rochester, MN, USA

L. G. Stead $(\bowtie)$

Generose G-410, Department of Emergency Medicine,

Mayo Clinic,

200 First Street SW,

Rochester, MN 55905, USA

e-mail: stead.latha@mayo.edu
Let's look at a few examples:

You are evaluating a patient with an acute ankle injury. Do you recognize the following questions?

- Unable to bear weight immediately and in ED?

- Tender on the lateral malleolar tip or posterior aspect of the lateral malleolus?

- Tender on the medial malleolar tip or posterior aspect of the medial malleolus?

Most practicing emergency medicine clinicians will recognize these as the questions used for the Ottawa ankle rule [1]. This was a prospective survey administered in two stages: derivation and refinement of the original rules (first stage) and validation of the refined rules (second stage). The cohort consisted of a convenience sample of adults with acute ankle injuries: 1,032 of 1,130 eligible patients in the first stage and 453 of 530 eligible patients in the second stage. While these research method details may seem not useful to daily clinical practice, the results derived from this study certainly are.

What about the following physical exam findings?

- No posterior midline cervical-spine tenderness

- No evidence of intoxication

- A normal level of alertness

- No focal neurologic deficit

- No painful distracting injuries

The above represent the NEXUS low risk criteria, which state that if a patent has all of the above, then they do not require cervical spine radiography [2]. This prospective observational study was conducted across 21 centers in the US. The study population consisted of 34,069 patients evaluated by imaging of the cervical spine after blunt trauma. Of these, $2.4 \%$ had radiographically documented cervical-spine injury. These results yielded an overall 
sensitivity of $99 \%$, specificity of $12.9 \%$, and a negative predictive value of $99.8 \%$. Again, while conducting such a study may not appeal to everyone, the results from such investigations do impact everyday patient care.

If the above two examples haven't convinced you clinical research directly impacts patient care, consider the following case:

- A 45-year-old male presents to the ED with chest pain of 2.5-h duration, radiating to the left arm, associated with diaphoresis, relieved by sublingual nitroglycerin in the ambulance, and rated 5/10. Family history is unknown.

What blood test will you order?

The troponin story [3]:

- 855 patients with symptoms of acute myocardial ischemia within $12 \mathrm{~h}$ of onset had serum troponin $\mathrm{T}$, $\mathrm{CK}-\mathrm{MB}$, and ECG done and analyzed in blinded fashion. Logistic regression was used to assess the usefulness of baseline levels of troponin T and CK-MB vs. ECG findings (ST-segment elevation, ST-segment depression, T-wave inversion, or the presence of confounding factors that impair the detection of ischemia). On admission, 289 of 801 patients with base-line serum samples had elevated troponin $\mathrm{T}$. Mortality within 30 days was significantly higher in these patients than in patients with lower levels of troponin $\mathrm{T}(11.8 \%$ vs. $3.9 \%, \mathrm{P}<0.001)$. Troponin $\mathrm{T}$ levels remained significantly predictive of 30-day mortality in a model that contained ECG categories and CK-MB levels (chi-square=9.2, $\mathrm{P}=0.027$ ). The authors of the study concluded that cardiac troponin $\mathrm{T}$ level is a powerful, independent risk marker in patients who present with acute myocardial infarction.
- Today, most clinicians routinely use this serum marker, perhaps not thinking about its origins from a research study.

So, why care about clinical research?

Clinical research is the way in which we can scientifically study patient outcomes and thus deliver evidencebased care. Our ED is our laboratory-where we are continually gathering, classifying, and analyzing data. While basic science and animal studies can provide important clues to the underlying pathophysiology of many human ailments, some nuances of human disease are not translatable from these models. Referred to as "the youngest science" by Lewis Thomas, the wonders of modern medicine are a direct result of medical research. Being involved in research offers the clinician the satisfaction of discovery and contributing to the care of those beyond the reach of her touch.

"The real voyage of discovery consists not in seeking new landscapes, but in having new eyes."

-Marcel Proust

\section{References}

1. Stiell et al (1993) Decision rule for radiography in acute ankle injuries: Refinement and prospective validation. JAMA 269 (9):1127-1132, Mar 3

2. Hoffman JR, Mower WR, Wolfson AB, Todd KH, Zucker MI (2000) Validity of a set of clinical criteria to rule out injury to the cervical spine in patients with blunt trauma. N Engl J Med 343:94-99

3. Ohman EM, Armstrong PW, Christenson RH, Granger CB, Katus HA, Hamm CW, O'Hanesian MA, Wagner GS, Kleiman NS, Harrell FE Jr, Califf RM, Topol EJ (1996) Cardiac troponin T levels for risk stratification in acute myocardial ischemia. GUSTO IIA Investigators. N Engl J Med 335(18):1333-1341, Oct 31 